\title{
Pengaruh Penyangraian Dengan Wajan Yang Berbeda Terhadap Kondisi Fisik dan Kualitas Organoleptik Seduhan Bubuk Kopi Liberika Tungkal Komposit (Libtukom)
}

\author{
${ }^{* 1}$ Ridawati Marpaung dan ${ }^{2}$ Al Fajri Suriyansah \\ ${ }^{1}$ Program Studi Agroklimatologi. Fakultas Pertanian Universitas Batanghari \\ ${ }^{2}$ Alumni Program Studi Agroklimatologi. Fakultas Pertanian Universitas Batanghari \\ Jl. Slamet Riyadi, Broni Jambi,36122. Telp.+620741-60603 \\ *1email korespondensi : marpaungridawati@yahoo.com
}

\begin{abstract}
This study aimed to determine the Effect of roasting with different pans on the organoleptic quality of tungkal composite liberica coffee brew (Libtukom). The expected outcome of this research was to increase the view of traditional coffee powder business actors about the use of a good roasting pan in the roasting process of coffee beans to produce good quality characteristics of coffee powder brewing and to add to the knowledge in the field of processing technology in plantation products. The research was carried out in Basic Agricultural Laboratory, Batanghari University. A Completely Randomized Design was implemented in as environmental design that used in this study. The treatment design were roasting with different types of pans, as follows: W1 = Iron skillet, W2 = Aluminum skillet, W3 = Earth skillet (pottery), W4 = Teflon skillet and W5 = Stainless Steel skillet. It was 3 timesrepeatation on each treatment. The results showed that the type of roasting pan had a significant effect on organoleptic quality included color, aroma, taste, bitterness of libtukom coffee powder brewing, but had no significant effect on the preference variables. The highest assessment of the preference variable was found in coffee powder that are roasted using aluminiumskillet.
\end{abstract}

Keywords: Liberika coffee, roasting, type of skillet, organoleptic quality, brewed coffee powder.

\begin{abstract}
Abstrak. Penelitian ini bertujuan untuk mengetahui pengaruh penyangraian dengan menggunakan wajan yang berbeda terhadap kondisi fisik dan kualitas organoleptik seduhan bubuk kopi liberika tungkal komposit (Libtukom). Luaran yang diharapkan dari penelitian ini adalah untuk meningkatkan pemahaman pelaku usaha bubuk kopi tradisional tentang penggunaan wajan sangrai yang baik dalam proses penyangraian biji kopi untuk menghasilkan karakteristik mutu organoleptik seduhan bubuk kopi baik dan untuk menambah khasanah ilmu pengetahuan dibidang teknologi pengolahan pada hasil perkebunan penelitian ini dilaksanakan pada bulan Mei - Juni 2020, di Desa Mekar Jaya Kecamatam Betara Kabupaten Tanjung Jabung Barat dan Laboratorium Dasar Fakultas Pertanian Universitas Batanghari. Rancangan lingkungan yang digunakan dalam pelaksanaan penelitian ini adalah Rancangan Acak Lengkap (RAL). Rancangan perlakuan yaitu penyangraian dengan jenis wajan berbeda, sebagai berikut: $\mathrm{W} 1$ = wajan besi, $\mathrm{W} 2$ = wajan aluminium, W3 = wajan tanah (Gerabah), W4 = wajan teflon dan W5 = wajan stainless stell. Setiap perlakuan dilakuakan pengulangan sebanyak 3 kali. Hasil penelitian menunjukkan jenis wajan sangrai berpengaruh nyata terhadap mutu organoleptik seperti warna, aroma, cita rasa, kepahitan seduhan bubuk kopi libtukom, tetapi tidak berpengaruh nyata terhadap peubah kesukaan. Penilaian tertinggi terhadap peubah kesuakaan terdapat pada bubuk kopi yang disangrai dengan menggunakan wajan aluminium.
\end{abstract}

Kata kunci : kopi liberika, penyangraian, jenis wajan, mutu organoleptik, seduhan bubuk kopi.

\section{PENDAHULUAN}

Kopi liberika adalah merupakan jenis kopi yang dapat tumbuh dan hidup subur di dataran rendah. Tanaman kopi liberika memiliki akar tunggang sehingga akan menyerap banyak air. Air banyak terdapat di daerah yang dataran rendah atau di lahan gambut, sehingga bentuk dari fisik liberika seperti pohon, daun, dan buah memiliki ukuran yang lebih besar dibandingkan jenis kopi lainnya. Selain itu kopi jenis liberika juga mempunyai sifat keunikan atau kekhasan dari rasanya, dimana bila dicicipi maka akan terasa aroma khas dari buah nangka (Pusat Penelitian Kopi dan Kakao Indonesia, 2014).

Untuk dapat menikmati seduhan bubuk kopi yang enak dan nikmat, biji kopi harus melewati beberapa proses. Pusat Penelitian Kopi dan Kakao Indonesia (2018) membagi proses pengolahan buah kopi yang dilakukan oleh industri maupun petani menjadi dua tahapan utama yaitu proses pengolahan produk primer dan produk sekunder kopi. Proses pengolahan produk primer kopi dimulai dari pengupasan kulit buah sampai pengemasan biji kopi kering. Sedangkan pengolahan produk sekunder kopi terdiri dari penyangraian biji kopi kering, pembubukan kopi sangrai dan pengemasan kopi bubuk. Mutu biji kopi sangat bergantung pada proses penanganan pascapanen yang tepat. Dengan penanganan pasca panen yang tepat disetiap prosesnya, mutu kopi bisa ditingkatkan (Yusdiali,2008).

Penyangraian merupakan suatu kegiatan pengolahan yang sangat penting untuk mengembangkan sifat organoleptik spesifik (aroma,rasa dan warna)yang mendasarikualitas kopi.Namun demikian, proses ini sangat kompleks,karena jumlah panasyang dipindahkan kebiji sangat penting. Panggabean (2012) dalam Purnamayanti, Gunadnya, Arda (2017) menyatakan suhu yang diperlukan dalam proses penyangraian biji kopi sekitar $60^{\circ} \mathrm{C}-$ $250^{\circ} \mathrm{C}$. Sedangkan lama penyangraian bergantung dari sistem dan tipe alat atau mesin penyangrai yang digunakan. 
Umumnya, waktu yang diperlukan untuk proses penyangraian sekitar 15-30 menit yang bertujuan untuk menjaga kualitas kopi dari segi warna kopi dan yang paling penting dari segi rasa kopi yang diinginkan.

Proses pengolahan biji kopi pasca panen yang dilakukan oleh petani di pedesaan sampai saat ini masih banyak dijumpai dilakukan dengan cara masih sangat tradisional dan kurang ekonomis untuk tetap diterapkan di era seperti saat ini.Permasalahan lain yang juga dihadapi petani pada saat penggorengan biji kopi adalah masih menggunakan wajan dan tungku tradisional, petani kesulitan untuk menentukan kematangan kopi secara merata,proses pengolahan kopi yang masih dilakukan secara konvensional dan belum banyak alat bantu yang membantu petani sebagai pelaku dalam proses pengolahan kopi. Purnama, Budiharti, Priyasmanu (2020), menyatakan bahwa penyangraian bisa dilakukan secara terbuka atau tertutup. Penyangraian secara tradisional umumnya dilakukan secara terbuka dengan menggunakan wajan terbuat dari tanah (kuali). Penyangraian kopi secara tertutup dengan menggunakan mesin-mesin yang harganya cukup mahal seperti batch roaster,sehingga tidak terjangkau oleh industri kecil yang modalnya terbatas.

Dari beberapa hasil penelitian yang dilakukan, penyangraian biji kopi secara tradisional menggunakan beberapa jenis bahan kuali menghasilkan mutu organoleptik yang berbeda. Menurut Sudaryanto (2016). Penggunaan kuali yang terbuat dari tanah liat (gerabah) dengan tungku kayu bakar memberikan hasil sangrai yang lebih merata dan aroma kopi lebih harum. Hasil penelitian menunjukkan bahwa parameter perubahan sifat fisik biji kopi matang lebih cepat terjadi pada wajan logam. Dari hasil uji kesukaan terhadap aroma dan rasa kopi bubuk semua panelis lebih menyukai kopi bubuk hasil sangrai menggunakan wajan gerabah dibandingkan dengan wajan logam.

Nugroho, Lumbanbatu, dan Rahayoe (2009) dalam penelitiannya melakukan penyangraian biji kopi menggunakan wajan teflon untuk mengetahui pengaruh suhu dan lama penyangraian terhadap sifat fisik mekanis biji kopi robusta. Dari hasil penelitian menunjukkan penggunaan wajan teflon dalam penyangraian menyebabkan suhu penyangraian lebih cepat mengalami kenaikan atau kurang stabil dibandingkan dengan wajan tanah liat, sehingga kopi lebih cepat menghitam. Wajan teflon merupakan penghantar panas yang baik sehingga panas dapat menyebar dengan cepat, sedangkan wajan tanah liat merupakan penghantar panas yang kurang baik. Bila digunakan sebagai wajan penyangrai biji kopi, peningkatan suhu terjadi perlahan-lahan sehingga biji kopi yang disangrai tidak mudah menghitam.

Petani kopi di Tanjung Jabung Barat sebagian besar belum menerapkan teknologi dalam penanganan pascapanen, sehingga proses pengolahan kopi yang dilakukan masih menggunakan peralatan manual serta cara tradisional. Petani kopi tersebut masih menggunakan peralatan penyangraian menggunakan wajan besi (MPIG, 2013).Tahap awal untuk memperoleh biji kopi yang bermutu baik diperlukan penanganan pasca panen yang tepat, melakukan setiap tahapan secara benar terutama proses fermentasi. Selama proses penyangraian kopi terdapat tiga tahapan reaksi fisik dan kimia yang terjadi pada biji kopi diantaranya ; penguapan air, penguapan senyawa volatil, dan proses pirolisis. Secara fisik proses pirolisis ditandai dengan adanya perubahan warna biji dari kehijauan menjadi kecoklatan kehitaman. Untuk mendapatkan kualitas organoleptik pada seduhan bubuk kopi, suhu dan waktu yang dibutuhkan dalam proses penyangraian berpengaruh terhadap tingkat kadar air dan keasaman (Yusdiali, Mursalim, dan Tulliza. 2008).

Berdasarkan beberapa penelitian yang menggunakan wajan yang berbeda dalam penyangraian biji kopi, maka dilakukan penelitian tentang pengaruh penyangraian menggunakan wajan yang berbeda terhadap mutu organoleptik seduhan bubuk kopi Liberika Tungkal Komposit (Libtukom).

\section{METODE PENELITIAN}

Penelitian ini dilaksanakan pada bulan Mei-Juni 2020. di Desa Mekar Jaya Kecamatam Betara Kabupaten Tanjung Jabung Barat dan Laboratorium Dasar Fakultas Pertanian Universitas Batanghari.

Bahan-bahan yang digunakan dalam penelitian ini adalah biji kopi liberika tungkal komposit dari petani kopi di Desa Mekar Jaya, Kecamatan Betara, Kabupaten Tanjung Jabung Barat. Alat yang digunakan antara lain wajan besi, wajan aluminium, wajan tanah, teflon, wajan stainles stell, mesin penggiling kopi, thermometer, kompor gas, ayakan, blender, alat tulis, oven, dan kertas gradasi warna.

Rancangan yang digunakan dalam pelaksanaan penelitian ini adalah rancangan acak lengkap (RAL). Rancangan perlakuan yaitu penyangraian dengan jenis wajan berbeda, sebagai berikut: w1 ; wajan besi ; w2 ; wajan aluminium ;w3 ; wajan tanah (derabah) ; w4 ; wajan teflon ; dan w5 ; wajan stainless stell. Setiap perlakuan dilakukan pengulangan sebanyak 3 kali, sehingga terdapat 15 unit percobaan.

Pelaksanaan penelitian ini diawali dengan kegiatan panen, pengupasan kulit buah, fermentasi, pengeringan, dan pengupasan kulit tanduk, dilaksanakan oleh petani kopi di Desa Mekar Jaya Kecamatan Betara Kabupaten Tanjung Jabung Barat. Penyangraian, penggilingan dan pengujian organoleptik dilaksanakan di Laboratorium dasar Fakultas pertanian Universitas Batanghari.

Peubah kondisi fisik dan organoleptik yang diamati dari seduhan bubuk kopi antara lain : warna, aroma, cita rasa, kepahitan dan kesukaan, sedangkan peubah yang diamati dari bubuk kopi adalah kadar air kering dan $\mathrm{pH}$. 
Analisis data yang digunakan untuk mengetahui perbedaan karakteristik mutu organoleptik seduhan bubuk kopi dilakukan sebagai berikut:

1. Pengamatan peubah warna, aroma, cita rasa, kepahitan, dan kesukaan dilakukan uji persepsi dengan skala likert 5 skala, kemudian ditabulasi data dan dilakukan analisis lanjutan DNMRT pada taraf $\alpha 5 \%$.

2. Pengujian peubah kadar air dan $\mathrm{pH}$ bubuk kopi dilakukan dengan analisis ragam dan analisi lanjutan DNMRT pada taraf $\alpha 5 \%$.

\section{Warna Bubuk Kopi}

\section{HASIL DAN PEMBAHASAN}

Hasil analisis ragam dan uji DNMRT taraf $\alpha=5 \%$, menunjukkan bahwa penggunaan jenis wajan sangrai yang berbeda, berpengaruh nyata terhadap warna bubuk kopi. Skor nilai warna bubuk kopi dengan jenis wajan sangrai yang berbeda dapat dilihat pada Tabel 1 berikut ini.

Tabel 1. Skor nilai warna bubuk kopi dengan wajan sangrai yang berbeda

\begin{tabular}{lcc}
\hline \multicolumn{1}{c}{ Perlakuan } & Skor & Warna Kopi* \\
\hline wajan teflon & $1,30 \mathrm{a}$ & sangat tidak hitam \\
wajan tanah & $2,47 \mathrm{~b}$ & tidak hitam \\
wajan besi & $3,73 \mathrm{c}$ & agak hitam \\
wajan aluminium & $4,03 \mathrm{~d}$ & hitam \\
wajan stainless & $4,87 \mathrm{e}$ & sangat hitam \\
\hline
\end{tabular}

Keterangan: Angka-angka yang diikuti huru kecil yang sama berbeda tidak nyata menurut uji DNMRT taraf $\alpha$ 5\% *:Interprestasi Skor Skala Likert 5 Skala

Hasil analisis statistika data peubah warna (Tabel 1) menunjukkan bahwa penyangraian menggunakan wajan stainless menghasilkan warna sangat hitam, wajan aluminium menghasilkan waran hitam, wajan besi menghasikan warna agak hitam, wajan tanah menghasilkan warna tidak hitam, dan penyangraian dengan wajan teflon menghasilkan warna sangat tidak hitam.

Pembentukan warna pertama kali ditentukan oleh proses fermentasi akibat aktivitas mikroorganisme dan reaksi enzimatis, kemudian oleh proses penyangraian. Pada penyangraian biji kopi dengan menggunakan wajan tanah (gerabah), penetrasi panas melalui gerabah ke biji kopi meningkat perlahan-lahan sehingga proses pematangan biji kopi berlangsung lebih baik dan pembentukan warna berlangsung lebih baik. Menurut Wilujeng dan Wikandari (2013) pada proses penyangraian terjadi pembentukan warna biji kopi kopi terjadi karena reaksi pencokelatan (reaksi millard), reaksi antara gugus amino pada asam amino membentuk melanoidin sehingga berpengaruh terhadap warna kopi.

\section{Aroma Bubuk Kopi}

Hasil analisis ragam dan uji DNMRT taraf $\alpha$ 5\%, menunjukkan bahwa penggunaan jenis wajan sangrai yang berbeda, berpengaruh nyata terhadap aroma bubuk kopi. Skor nilai aroma bubuk kopi dengan jenis wajan sangrai yang berbeda dapat dilihat pada Tabel 2 berikut ini.

Tabel 2. Skor nilai aroma bubuk kopi dengan wajan sangrai yang berbeda

\begin{tabular}{lcc}
\hline \multicolumn{1}{c}{ Perlakuan } & Skor & Aroma Kopi* \\
\hline wajan teflon & $2,43 \mathrm{a}$ & tidak disukai \\
wajan tanah & $2,93 \mathrm{~b}$ & tidak disukai \\
wajan stainless & $3,30 \mathrm{bc}$ & agak disukai \\
wajan besi & $3,63 \mathrm{c}$ & agak disukai \\
wajan aluminium & $3,70 \mathrm{c}$ & agak disukai \\
\hline
\end{tabular}

Keterangan: Angka-angka yang diikuti huru kecil yang sama berbeda tidak nyata menurut uji DNMRT taraf $\alpha$ 5\% *:Interprestasi Skor Skala Likert 5 Skala

Dari Tabel 2. menunjukkan bahwa penyangraian menggunakan wajan aluminium, wajan besi, dan wajan stainless menunjukkan hasil agak disukai dengan skor 3,70 likert 3, 63 likert dan 3,30 likert. Sedangkan wajan tanah dan wajan teflon menunjukkan hasil tidak disukai oleh panelis dengan skor 2,92 likert dan 2,43 likert.

Penyangraian biji kopi dilakukan untuk mendapatkan aroma dari biji kopi saat akan diseduh. Penyangraian biji kopi dengan waktu penyangraian 20 menit, aroma biji seduhan khas bubuk kopi lebih tajam karena pemasakan kopi lebih cepat, sedangkan penyangraian biji kopi dengan menggunakan wajan tanah dan Teflon, kemasakan biji kopi belum cukup matang sehingga aroma yang dihasilkan pada seduhan bubuk kopi kurang tajam. Menurut Mulato dalam Wilujeng dan Wikandari (2013), penyangraian menyebabkan terjadinya pirolisasi sehingga senyawa volatile 
Ridawati Marpaung dan Al Fajri Suriyansah. Pengaruh Penyangraian Dengan Wajan Yang Berbeda Terhadap Kondisi Fisik dan Kualitas Organoleptik Seduhan Bubuk Kopi Liberika Tungkal Komposit (Libtukom)

menguap yang mengakibatkan adanya aroma pada kopi, senyawa volatil furan dapat menimbulkan aroma karamel, oxazole beraroma sweet hazelbut, fenol bearoma bitter, dan pyrazine beraroma sweet biiter.

\section{Cita Rasa Kopi}

Hasil analisis ragam dan uji DNMRT taraf $\alpha$ 5\%, menunjukkan bahwa penggunaan jenis wajan sangrai yang berbeda, berpengaruh nyata terhadap cita rasa kopi. Skor nilai cita rasa kopi dengan jenis wajan sangrai yang berbeda dapat dilihat pada Tabel 3 berikut ini.

Tabel 3. Skor nilai cita rasa kopi dengan wajan sangrai yang berbeda

\begin{tabular}{lcc}
\hline \multicolumn{1}{r}{ Perlakuan } & Skor & Cita Rasa Kopi* \\
\hline wajan tanah & $2,53 \mathrm{a}$ & tidak disukai \\
wajan teflon & $3,00 \mathrm{ab}$ & agak disukai \\
wajan stainless & $3,03 \mathrm{ab}$ & agak disukai \\
wajan besi & $3,23 \mathrm{ab}$ & agak disukai \\
wajan aluminium & $3,50 \mathrm{~b}$ & agak disukai \\
\hline
\end{tabular}

Keterangan: Angka-angka yang diikuti huru kecil yang sama berbeda tidak nyata menurut uji DNMRT taraf $\alpha$ 5\% *:Interprestasi Skor Skala Likert 5 Skala

Hasil analisis statistika data peubah cita rasa (Tabel 3) menunjukkan bahwa penyangraian menggunakan wajan aluminium, wajan besi, wajan stainless, dan wajan teflon agak disukai oleh panelis, dengan skor masingmasing secara berurutan 3,50 likert, 3,23 likert, 3,03 likert, dan 3,00 likert. Sedangka cita rasa seduhan kopi hasil sangrai wajan tanah tidak disukai oleh panelis dengan skor 2,53 likert.

Cita rasa seduhan bubuk kopi hasil penyangraian dengan wajan aluminium, stainless dan Teflon lebih baik dibandingkan penyangraian dengan kuali tanah karena hasil penyangraian dengan menggunakan kuali tanah biji kopi belum matang secara sempurna karena penetrasi panas dari kuali tanah ke biji kopi lebih lambat bila dibandingkan dengan penyangraian dengan kuali aluminium, besi, stainless, dan Teflon. Penelitian yang dilakukan oleh Sari (2001) menyatakan bahwa cita rasa kopi terjadi akibat proses pemanasan dalam penyangraian sehingga terjadi degradasi beberapa senyawa seperti karbohidrat, alkaloid, asam klorogenat, senyawa volatil, dan trigonelin. Karbohidrat terdegradasi menjadi glukosa dan gula-gula sederhana yang menghasilkan rasa manis. Dalam penyangraian, alkaloid adalah kafein mengalami sublimasi membentuk kafeol. Kafein, asam klorogenat dan trigenelin menghasilkan rasa pahit pada seduhan bubuk kopi.

\section{Kepahitan}

Hasil analisis ragam dan uji DNMRT taraf $\alpha$ 5\%, menunjukkan bahwa penggunaan jenis wajan sangrai yang berbeda berpengaruh nyata terhadap kepahitan kopi. Skor nilai kepahitan kopi dengan jenis wajan sangrai yang berbeda dapat dilihat pada Tabel 4 berikut ini.

Tabel 4. Skor nilai kepahitan kopi dengan wajan sangrai yang berbeda

\begin{tabular}{ccc}
\hline Perlakuan & Skor & Kepahitan* \\
\hline wajan teflon & 1,97 & sangat tidak pahit \\
wajan tanah & 2,40 & tidak pahit \\
wajan besi & 3,23 & agak pahit \\
wajan aluminium & 3,40 & agak pahit \\
wajan stainless & 4,53 & pahit
\end{tabular}

Keterangan: Angka-angka yang diikuti huru kecil yang sama berbeda tidak nyata menurut uji DNMRT taraf $\alpha$ 5\% *:Interprestasi Skor Skala Likert 5 Skala

Dari Tabel 4, menunjukkan bahwa penyangraian menggunakan wajan stainless menunjukkan tingkat kepahitan dengan skor 4,53 likert (pahit). Kopi yang disangrai dengan wajan aluminium dan besi menunjukkan tingkat kepahitan yang agak pahit dengan skor 3,40 likert dan 3,23 likert. Kopi yang disangrai dengan wajan tanah menunjukkan tingkat kepahitan tidak pahit dengan skor 2,40 likert. Sedangkan kopi yang disangrai dengan wajan teflon menunjukkan tingkat kepahitan sangat tidak pahit dengan skor 1,97 likert. Tingkat kepahitan seduhan bubuk kopi lebih tinggi pada penyangraian dengan wajan aluminium dan besi karena penyangraian dengan waktu 20 menit, kemasakan biji kopi lebih matang disbanding dengan menggunakan wajan tanah dan Teflon. Biji kopi yang lebih matang akan menghasilkan kepahitan lebih tinggi dibandingkan yang belum matang. Rasa pahit timbul karena adanya reaksi kimia saat penyangraian biji kopi. Rangkaian reaksi kimia mengubah asam klorogenik menjadi chologenic acid lactone, kemudian akibat penyangraian pada suhu yang tinggi secara terus-menerus akan 
Ridawati Marpaung dan Al Fajri Suriyansah. Pengaruh Penyangraian Dengan Wajan Yang Berbeda Terhadap Kondisi Fisik dan Kualitas Organoleptik Seduhan Bubuk Kopi Liberika Tungkal Komposit (Libtukom)

membentuk senyawa hasil pemecahan lactone, yaitu phenylindane, senyawa yang bertanggung jawab atas munculnya rasa pahit pada kopi (Sari, 2001).

\section{Kesukaan}

Hasil analisis ragam dan uji DNMRT taraf $\alpha$ 5\%, menunjukkan bahwa penggunaan jenis wajan sangrai yang berbeda, tidak berpengaruh nyata terhadap tingkat kesukaan kopi. Skor nilai kesukaan terhadap kopi dengan jenis wajan sangrai yang berbeda dapat dilihat pada Tabel 5 berikut ini.

Tabel 5. Skor nilai kesukaan kopi dengan wajan sangrai yang berbeda

\begin{tabular}{ccc}
\hline Perlakuan & Skor & Kesukaan* \\
\hline wajan tanah & $2,83 \mathrm{a}$ & tidak disukai \\
wajan teflon & $2,90 \mathrm{a}$ & tidak disukai \\
wajan stainless & $3,10 \mathrm{a}$ & agak disukai \\
wajan besi & $3,33 \mathrm{a}$ & agak disukai \\
wajan aluminium & $3,40 \mathrm{a}$ & agak disukai \\
\hline
\end{tabular}

Keterangan: Angka-angka yang diikuti huru kecil yang sama berbeda tidak nyata menurut uji DNMRT taraf $\alpha$ 5\% *:Interprestasi Skor Skala Likert 5 Skala

Dari Tabel 5 menunjukkan bahwa seduhan bubuk kopi yang agak disukai oleh panelis adalah dri bubuk kopi yang disangrai dengan menggunakan wajan aluminium, wajan besi, dan wajan stainless. Hal ini sejalan dengan pembahasan pada peubah warna, citarasa, aroma dan kepahitan seduhan bubuk kopi, dimana tingkat kematangan sangrai biji kopi dengan menggunakan wajan aluminium, besi dan stainless lebih cepat dan lebih matang dibandingkan wajan Teflon dan wajan tanah dalam waktu 20 menit. Sedangkan kopi yang disangrai dengan wajan teflon dan tanah tidak disukai oleh para panelis. Dengan demikian pembentukan warna, aroma, citarasa dan kepahitan seduhan bubuk kopi lebih baik dan disukai oleh panelis. Apabila biji kopi sangria tidak matang sempurna, kualitas warna, citarasa, aroma dan kepahitan kurang baik karena belum mengalami reaksi-reaksi kimia sebagaimana disebut di pembahasan terdahulu.

\section{pH Seduhan Kopi}

Hasil analisis ragam dan Uji DNMRT dengan taraf a 5\%, menunjukkan bahwa penggunaan jenis wajan sangrai yang berbeda, berpengaruh nyata terhadap $\mathrm{pH}$ seduhan kopi. $\mathrm{pH}$ seduhan kopi dengan jenis wajan sangrai yang berbeda dapat dilihat pada Tabel 6 berikut ini.

Tabel 6. $\mathrm{pH}$ seduhan kopi dengan wajan sangrai yang berbeda

\begin{tabular}{cc}
\hline Perlakuan & Skor \\
\hline wajan tanah & $5,00 \mathrm{a}$ \\
wajan besi & $5,10 \mathrm{~b}$ \\
wajan teflon & $5,23 \mathrm{c}$ \\
wajan aluminium & $5,26 \mathrm{c}$ \\
wajan stainless & $5,93 \mathrm{~d}$ \\
\hline
\end{tabular}

Keterangan: Angka-angka yang diikuti huru kecil yang sama berbeda tidak nyata menurut uji DNMRT taraf $\alpha$ 5\%

Dari Tabel 6, menunjukkan bahwa penggunaan jenis wajan sangrai yang berbeda berpengaruh nyata terhadap $\mathrm{pH}$ seduhan kopi. Nilai rata-rata $\mathrm{pH}$ seduhan kopi berada pada 5,00 - 5,93. Dimana nilai $\mathrm{pH}$ terendah adalah kopi hasil sangrai dengan menggunakan wajan tanah, sedangkan nilai $\mathrm{pH}$ tertinggi adalah kopi hasil sangrai dengan menggunakan wajan stainless. Tingginya $\mathrm{pH}$ seduhan bubuk kopi dengan penyangraian menggunakan wajan stailess adalah karena penyangraian biji kopi dengan menggunakan wajan stainless kematangan sangrai biji kopi dalam waktu 20 menit lebih cepat sehingga pemecahan asam asam organik dalam biji kopi lebih cepat sehingga tingkat keasaman seduhan bubuk kopi mengalami penurunan atau $\mathrm{pH}$ meningkat.

\section{Kadar Air Bubuk Kopi}

Hasil analisis ragam dan uji DNMRT taraf $\alpha$ 5\%, menunjukkan bahwa penggunaan jenis wajan sangrai yang berbeda berpengaruh nyata terhadap kadar air bubuk kopi. Kadar air bubuk kopi dengan jenis wajan sangrai yang berbeda dapat dilihat pada Tabel 7 berikut ini. 
Ridawati Marpaung dan Al Fajri Suriyansah. Pengaruh Penyangraian Dengan Wajan Yang Berbeda Terhadap Kondisi Fisik dan Kualitas Organoleptik Seduhan Bubuk Kopi Liberika Tungkal Komposit (Libtukom)

Tabel 7. Kadar air bubuk kopi dengan wajan sangrai yang berbeda

\begin{tabular}{ll}
\hline Perlakuan & Skor \\
\hline Wajan Stainless & $2,13 \mathrm{a}$ \\
Wajan Aluminium & $2,80 \mathrm{~b}$ \\
Wajan Tanah & $2,93 \mathrm{~b}$ \\
Wajan Besi & $3,00 \mathrm{~b}$ \\
Wajan Teflon & $3,55 \mathrm{c}$ \\
\hline
\end{tabular}

Keterangan: Angka-angka yang diikuti huru kecil yang sama berbeda tidak nyata menurut uji DNMRT taraf $\alpha$ 5\% *:Interprestasi Skor Skala Likert 5 Skala

Dari Tabel 7, menunjukkan bahwa penggunaan jenis wajan sangrai yang berbeda, berpengaruh nyata terhadap kadar air bubuk kopi. Kadar air bubuk kopi hasil penyangraian dengan wajan stailess lebih rendah dibandingkan kadar air yang disangrai dengan wajan lainnya karena penetrasi panas dari wajan stainless ke biji kopi selama penyangraian lebih cepat sehingga penguapan air lebih cepat. Semakin besar perbedaan antar suhu medium pemanas dan sampel dalam penyangraian, maka proses penguapan air bubuk kopi akan semakin cepat, dengan demikian kadar air bubuk kopi lebih rendah.

\section{KESIMPULAN}

Berdasarkan hasil penelitian dan pembahasan dapat ditarik kesimpulan sebagai berikut : Jenis wajan sangrai berpengaruh nyata terhadap mutu organoleptik yaitu warna, aroma, cita rasa, kepahitan seduhan bubuk kopi libtukom, tetapi tidak berpengaruh nyata terhadap peubah kesukaan dan penilaian tertinggi terhadap peubah kesuakaan terdapat pada bubuk kopi yang disangrai dengan menggunakan wajan aluminium.

\section{DAFTAR PUSTAKA}

Balai Pengkajian Teknologi Pertanian Jambi. 2014. Mengenal Kopi Liberika Tungkal Komposit (LIBTUKOM). Jambi (online) diakses tanggal 22 Januari 2019.

Natawidjaya. H., M. Unggul Ametung., E. Suharyanto., S. Mulato., dan Dedi (2012). Pedoman Teknis penanganan pasca panen Kopi. Direktorat pasca panen dan pembinaan Usaha. Direktorat Jendral Perkebunan. Kementrian Pertanian.

Marliah. 2012. Sifat Kimia dan Evaluasi Sensorik Bubuk Kopi Arabika. Jurnal Floratek Vol 7.

Nugroho, J, Lumbanbatu, J dan Rahayoe, S. 2009. Pengaruh Suhu dan Lama Penyangraian Terhadap Sifat FissikMekanis Biji Kopi Robusta. Makalah Bidang Teknik Produk Pertanian, ISSN 2081-7152 diakses dari :https://repository.ugm.ac.id/33122/1/a20_Joko_Nugroho.pdf

Purnama, P.Z, N.Budiharti, T.Priyasmanu (2020), Rancang Bangun MesinOven Kopi dengan Prinsip QFD dan Ergonomi Program Studi Teknik Industri S1, Fakultas Teknologi Industri, Institut Teknologi Nasional Malang. Jurnal Valtecch (Jurnal Mahasiswa Teknik Industri). E-ISSN. 2614-8382. Volume 3 No 2 (2020)

Purnamayanti N.P.A, I. Bagus Putu Gunadnya, G.Arda (2017), Pengaruh Suhu dan Lama Penyangraian terhadap Karakteristik Fisik dan Mutu Sensorik Kopi Arabika (Coffea arabica L.). Program Studi Teknik Pertanian, Fakultas Teknologi Pertanian Unud

Putra Tani. 2017. Mengenal dan Budidaya Kopi Liberika. http://putratani.com/mengenal-dan-budidaya-kopiliberika/ ; Diakses pada 06 Februari 2019.

Sudaryanto., A (2016). Pemanfaatan Wajan gerabah Sangrai Kopi Pada Unit usaha Mikro Kopi Bubuk di Sumba Barat Daya NTT.Pusat Pengembangan Teknologi Tepat Guna Lembaga Ilmu pengetahuan Indonesia (LIPI) Subang. Seminar Nasional IENACO 